\title{
Putative Pacemakers in Crayfish Procambarus clarkii Show Circadian Oscillations in Levels of mRNA for Clock Genes under Different Light Rhythm
}

\author{
Wei Xie ${ }^{1}$, Bin Sun ${ }^{1}$, Peng $\mathrm{Li}^{1, *}{ }^{-}$, Jie Yan $^{1, *}\left(\mathbb{D}\right.$, Wan Chen ${ }^{2}$, Kaiya Zhou ${ }^{1}$ \\ ${ }^{1}$ Jiangsu Key Laboratory for Biodiversity and Biotechnology, College of Life Sciences, Nanjing Normal University, \\ Nanjing 210023, China. \\ ${ }^{2}$ College of the Environment and Ecology, Jiangsu Open University, Nanjing 210036, China.
}

\section{Article History}

Received February 15, 2020

Accepted October 22, 2020

First Online October 23, 2020

\section{Corresponding Author \\ Tel.: +862585891605, \\ $+862585891605$ \\ E-mail: lipeng@njnu.edu.cn, yanjie@njnu.edu.cn}

\section{Keywords}

Procambarus clarkia

Clock genes

Circadian oscillations

mRNA expression

\begin{abstract}
In the circadian rhythm mechanism, cycle $(\mathrm{Cyc})$, clock (Clk), cryptochrome (Cry) are three core clock genes that constitute complex mechanism controlling organisms to follow a 24-hour oscillation cycle. In the present study, the major clock genes, i.e. PcCyc, PcClk, PcCry1 were cloned from crayfish Procambarus clarkii. The putative functions as well as physical and chemical properties of the resolved proteins were analyzed by various bioinformatic methods. Real-time quantitative PCR technique was used to explore the mRNA expression of the PcCyc, PcClk, PcCry1 in brain, eyestalk, and hepatopancreas tissues of $P$. clarkii. In order to examine circadian rhythm of selected clock genes in the species, the experiment was carried out under three different light conditions, namely: (a) $12 \mathrm{~h}$ of light and dark periods per day (12LD), (b) $24 \mathrm{~h}$ of constant darkness (24DD) and (c) $72 \mathrm{~h}$ of constant darkness (72DD). The obtained results showed essential correlation in the mRNA expression levels of PcCyc and PcClk genes under similar light conditions. It indirectly suggests that the PcCYC and PcCLK proteins might be involved in the transcriptomic regulatory mechanism of all other genes within the core-clock network. The mRNA expression levels of the PcCry1 gene were highly variable, differing significantly in relation to the various illumination conditions and sampled tissues. The obtained results seem to follow the pattern evidencing the sensitivity of PcCry1 gene to the light signals. It firmly supports the gene's role in the conversion mechanism of light signals into optical signals, which is engaged in the generation and control of circadian rhythmicity.
\end{abstract}

\section{Introduction}

The circadian clock is widespread mechanism observed from bacteria and fungi to plants and animals, being responsible for generation and control selfsustained oscillations of physiology, biochemistry and behavior in the course of the $24 \mathrm{~h}$ periodicity of day and night cycles (Young \& Kay, 2001). It has been confirmed that circadian clock genes regulate organism's homeostasis, including: inflammation responses, blood sugar balance, synthesis and catabolism (Sancar et al., 2015), etc. The biological foundation of circadian clock rhythm relies on the positive feedback loop of protein factors, such as CLK/BMAL1 and the negative feedback loop that depends on protein factors, such as CRY. It was evidenced that alike clock genes as: Period (Per), Timeless (Tim) and pigment dispersing factor ( $p d f)$ also regulate the mechanism. Generally, the circadian rhythm mechanism consists the central clock and the peripheral clocks of organization, which together maintain biological cycles (Lee et al., 1998; Rudic et al., 2004; Fuhr et al., 2015). So far, the extensive studies on clock genes in Drosophila have provided many important information on its biological regulating 
effects (Plautz et al., 1997). Accordingly, in the Drosophila system the clock ( $\mathrm{Clk})$ and cycle $(\mathrm{Cyc})$ genes produce proteins CLK and CYC that form CLK-CYC heterodimers, which enter the nucleus as a transcription factor, and bind to the E-box region (CACGTG) in the promoter site of downstream Per and Tim genes. The transcription of Per and Tim genes is activated, and the product proteins PER and TIM monomers accumulate in the cytoplasm and form PER-TIM heterodimer, then enter the nucleus and bind to CLK-CYC. As a result, CLKCYC cannot bind to the E-box region, thereby suppressing the transcription of Per and Tim genes and forming a complete Per/Tim feedback loop (Beaver \& Giebultowicz, 2004).

In vertebrates the Arntl gene, sometimes called Bmal1 (brain and muscle ARNT-like protein 1) is known as homologous of $C y c$ gene, being considered as one of the most important core transcription factors regulating the circadian clock. The gene encodes BMAL1 protein, which is classified as bHLH/PAS transcription factor (Ikeda \& Nomura, 1997; Zhang et al., 2013). In turns, the Clk gene is the first cloned circadian clock gene in mammals, which has laid the foundation to consecutive studies (King et al., 1997). Both CLK and Bmal1 proteins are members of the basic helix-loop-helix (bHLH)/PERARNT-SIM (PAS) super family of transcription factors. Moreover, Clk and Bmal1 genes show high similarity, encoding both a DNA-binding and protein dimerization domains, which are strongly conservative. Another important core clock gene Cry was firstly found in plants, but further studies evidenced that it has homologues in various animals (Sancar, 2003). The encoded by Cry gene, the blue/UV-A absorbing photo protein, called as cryptochrome (CRY), which beside its transcription repression function is known as an photoreceptor that directly modulates light input into the circadian clock (Stanewsky, 2002; Hoang et al., 2008; Song et al., 2007; Heyers et al., 2007; Ozturk et al., 2011). Subsequent studies found two types of cryptochrome genes (Cry1 and Cry2) in crustaceans, which suggests biological clock in crustaceans is more similar to that in butterflies than in fruit flies (Tilden et al., 2011).

Up to date, many clock genes have been identified or their expressional patterns and functions have been detected in crustaceans. For instance, Zhang et al. (2013) cloned the clock genes of Eurydice pulchra, and found that the tidal rhythm is driven by a special circadian pacemaker. Chesmore et al. (2016) discovered that the clock genes in Homarus americanus are highly conserved. In turns, O'Grady et al. (2016) reported the sequence of major genes in the circadian clock of the Talitrus saltator and identified that the clock-related genes showed temporal changes in expression. It was found that in Daphnia pulex genes of many functional groupings, e.g. related to immunity, oxidative detoxification and sensory process exhibit $24 \mathrm{~h}$ rhythms in their expression patterns under diel conditions (Rund et al., 2016).
Multiple endogenous and exogenous factors, such as: environmental temperature, light condition and physiological status, usually regulate the fluctuation of circadian clock gene transcript levels (Boothroyd et al., 2007; Gegear et al., 2008; Yan et al., 2013). Photoperiodism is the length of light or dark period per day, which has been identified to be related to varieties of associated physiological states including diapause, seasonal morphs and growth rate in many insects (Saunders, 2010). It is widely accepted that a circadian clock is involved in the photoperiodic response (Goto, 2013). Fanjul-Moles and colleagues (2004) assumed that circadian rhythm of $P$. clarkii is regulated by blue light through the hypothetical additional retinal photoreceptors. Intriguingly, biochemical analyses showed that the circadian physiological functions of PER, TIM and CLK proteins and their composition in the cytoplasm and nucleus of the retina and optic lobes varies in time according to diurnal oscillations (Escamilla-Chimal et al., 2010). In addition, sensitivity of rhodopsin in the retina of $P$. clarkii to light can cause changes in rhythm, which in turn leads to an increase or decrease in glucagon $(\mathrm{CHH})$.

Based on the previous researches, we know that the core clock proteins (CLK, CYC, TIM, PER) interact in the brain, regulating the diel rhythm of $P$. clarkii. The light signals are received through the tissue of eyestalk in $P$. clarkii, which regulates the transcription of CRY protein, and then participates in regulating the clock network. In the crayfish $P$. clarkii, circadian pacemaker localization has been proved to be in the protocerebrum of the cerebroid ganglion (Escamilla-Chimal et al., 2010; Nelson-Mora et al., 2013). The sinus gland was found to be located in the eyestalk and formed by the axonal assembly of a specific neurons group that constitutes the X-organ (García \& Aréchiga, 1998). The most relevant source of the core biological clock control is attributed to the X-organ-sinus gland and brain tissue of circadian pacemaker. Therefore, the eyestalk and brain are both central clock tissues, which receive and process external signals, playing a central role in the regulation of biological clock genes. It is known that the central circadian clock synchronizes the peripheral clocks in the tissues of hepatopancreas and cardiac neuromuscular system (Christie et al., 2018).

The red-swamp crayfish Procambarus clarkii is an important freshwater economic species in aquatic products market of China (the total annual production in 2019 is $1.638,700$ million tons, market value is $\sim 54.92$ billion dollars). In the process of aquaculture, clarifying the regularities of behavior, physiology, feeding and reproduction of economic species and their molecular background can provide scientific elaboration of sustainable aquaculture models, for instance, for better food intake, decrease of aggressive behaviour, cannibalism, etc. Although clock genes have been studied thoroughly in model animals, the regulatory mechanism in aquatic crustaceans is still unclear. Since the discovery of clock genes in crustaceans, most of 
carried out research have focused mainly on the mechanisms maintaining rhythmic oscillations and their effects on the rhythm of life activities (Fanjul-Moles \& Prieto-Sagredo, 2003; Grabek \& Chabot, 2012; Manfrin et al., 2015). Here we cloned full-length or partial cDNA of Cyc, Clk, and Cry1 (denoted as PcCyc, PcClk, and PcCry1) and investigated the expression patterns of the circadian clock genes in different tissues (brain, eyestalk, and hepatopancreas) from $P$. clarkii as well as under three different lighting conditions (12LD, 24DD, 72DD).

\section{Materials and Methods}

\section{Ethics Statement}

Animal welfare and experimental procedures were approved by the Institutional Animal Care and Use Committee of Nanjing Normal University [SOXR (Jiangsu) 2015-028]. The authors confirmed that animals did not suffer unnecessarily at any stage of experiments in this study.

\section{Animals and Experimental Design}

All the adult males of Procambarus clarkii used in this study were field-collected from Xuzhou City, Jiangsu, China. The healthy crayfish were acclimatized for two weeks in the laboratory aquaria with adequate aeration at $25^{\circ} \mathrm{C}$ in a $12 \mathrm{~h}$ of light and dark regimes of daily photoperiod. All specimens were fed with commercially crayfish food with daily dosage $3 \%$ of specimens biomass. The aquaria were equipped with polyvinyl tubes simulating burrows, which allowed the crayfish to hide from the light. After acclimatization, the crayfish were divided into three groups. The first group was directly used for examination after two weeks of acclimation. The second and third group ( $\mathrm{N}=63$ per each group) was exposed to continuous darkness (DD) for 24 $h$ and $72 h$, respectively. At the end of each treatment, nine specimens from each group were randomly selected at seven different times (Day1, 7:00 am, 11:00 am, 15:00 pm, 19:00 pm, 23:00 pm. Day2, 3:00 am, 7:00 am). All samples from each group at different time points and from different tissues (brain, eyestalk, and hepatopancreas) of $P$. clarkii were preserved in RNAlater RNA Stabilization Reagent (QIAGEN, Germany) after dissection. The tissue samples were cut into tiny particles (less than $0.2 \mathrm{~mm}$ thick) and placed in separate tubes, then kept overnight at $4^{\circ} \mathrm{C}$ and finally stored at $20^{\circ} \mathrm{C}$ before total RNA isolation.

\section{RNA Extraction and cDNA Synthesis}

Total RNA was extracted from the all collected tissues of $P$. clarkii using TransZol ${ }^{\mathrm{TM}}$ Up Plus RNA Kit (TransGen, Beijing, China) according to the product manual. RNA purity was verified by measuring the absorbance at 260 and $280 \mathrm{~nm}$ by a NanoDrop ND2000C spectrophotometer (NanoDrop Technologies,
Wilmington, DE, USA) and RNA integrity was checked by electrophoresis on $1.0 \%$ agarose gel. The cDNA for each sample was synthesized from the same amount of total RNA $(0.5 \mu \mathrm{g})$ by PrimeScript ${ }^{\mathrm{TM}}$ RT reagent Kit with gDNA Eraser (Perfect Real Time) (TaKaRa, Dalian, China) following the manufacturer's protocol. Finally, the obtained cDNAs were stored at $-80^{\circ} \mathrm{C}$ until further processing.

\section{Cloning of Full-length cDNAs of PcCyc, PcClk and PcCry1}

The full-length PcCyc and PcCry1 cDNA, partical PcClk cDNA were derived by using the rapid amplification of cDNA ends (RACE) method. The partial cDNA sequences of $C y c, C l k$, and $C r y 1$ was used to design degenerate primers, based on the nucleotide sequence data available for $P$. clarkii in the NCBI GenBank (Accession code: SPR044128) (Shen et al., 2014).

The PCR reactions were conducted using firststrand CDNA from the eyestalk tissue as template. The PCR program included denaturation stage at $95^{\circ} \mathrm{C}$ for 5 min, following 29 cycles of annealing at $95^{\circ} \mathrm{C}$ for $30 \mathrm{~s}$ and elongation at $62^{\circ} \mathrm{C}$ for $30 \mathrm{~s}$, then the final extension stage was carried out at $72^{\circ} \mathrm{C}$ for $1 \mathrm{~min}$. The PCR reactions were completed an additional extension stage at $72^{\circ} \mathrm{C}$ for $10 \mathrm{~min}$. The product was evaluated by $1.0 \%$ agarose gel electrophoresis to exclude the presence of nonspecific amplification and primer dimers.

\section{Sequence and Phylogenetic Analysis}

Bioinformatics analyses of the obtained PcCyc, PcClk, and PcCry1 gene sequences were performed using the BLAST tool (http://www.ncbi.nlm.nih.gov/BLAST/) on National Center for Biotechnology Information (NCBI) to verify the full-length integrity of cDNA sequences. The online ORF Finder (http://ncbi.nlm.nih.gov/gorf/gorf.html) was used for finding open reading frames of the analyzed clock genes. The deduced proteins domains were analyzed using SMART online analysis programs (http://smart.embl-heidelberg.de/) and Motif Scan online server (https://myhits.isb-sib.ch/cgibin/motif_scan) (Hulo et al., 2008). The SignalP 4.1 online server (http://www.cbs.dtu.dk/services/SignalP/) (Nielsen \& Krogh, 1998; Petersen et al., 2011) was used to locate the signal peptide of the CYC, CLK and CRY1 proteins. The PSIPRED online server (http://bioinf.cs.ucl.ac.uk/psipred_new/) was used to resolve secondary structure of each protein. The threedimensional (3D) structure of PcCYC, PcCLK, and PcCRY1 were constructed using SWISS-MODEL (https://swissmodel.expasy.org/).

\section{Quantitative Real-time PCR}

One microgram of previously isolated RNA was used to synthetize the first-strand cDNA with the 
Primescript $^{\mathrm{Tm}}$ RT reagent Kit with gDNA Eraser (Perfect Real Time) (TaKaRa, Dalian, China). Next, one microliter $(0.5 \mu \mathrm{g} / \mu \mathrm{L})$ of 10 -fold diluted of amplified CDNA template was used for quantitative real-time PCR. The RT-qPCR reactions were performed in a total of $20 \mu \mathrm{L}$ reaction mixture using $\mathrm{SYBR}^{\oplus}$ Premix Ex Taq $^{\text {Tm }}$ ॥ kit (TaKaRa, Japan). The RT-qPCR conditions were as follows: a pre-denaturation stage at $95^{\circ} \mathrm{C}$ for $10 \mathrm{~min}$, followed by 40 cycles of quantification stage: $95^{\circ} \mathrm{C}$ for 15 $\mathrm{s}$ and $60^{\circ} \mathrm{C}$ for $1 \mathrm{~min}$ as well as melting curves analysis stage: $95^{\circ} \mathrm{C}$ for $15 \mathrm{~s}, 60^{\circ} \mathrm{C}$ for $1 \mathrm{~min}$ and $95^{\circ} \mathrm{C}$ for $15 \mathrm{~s}$. The relative expression level of target gene was analyzed by compare Ct $\left(2^{-\Delta \Delta C t}\right)$ method (Livak \& Schmittgen, 2001). The reactions and samples were carried out in triplicate and the expression levels were normalized to that of $B$ actin reference gene. All the primers used for RT-qPCR were shown in Table 1. RT-qPCR data (see data in Appendix_data_file_S1) were analyzed using SPSS software 13.0 (SPSS Inc., Chicago, IL, USA) with one-way analysis of variance (ANOVA) and Duncan's multiple comparative analysis. For each value category the mean \pm standard deviation (SD) values were reported. The weightiness of observed differences in expression levels were determined by applied statistical tests, assuming the significance criterion at $\alpha=0.05$.

\section{Results}

\section{Cloning and Sequence Analysis}

One fragments (312 bp) was amplified by $5^{\prime}$-RACE technique from the $5^{\prime}$ end of each cDNA and several other fragments $(1,185 \mathrm{bp}$ and $1,129 \mathrm{bp})$ were amplified by $3^{\prime}$-RACE technique. The full-length cDNA of the studied genes (nucleotide and amino acid sequences shown in Appendix_data_file_S1) was verified by BLAST from the National Center for Biotechnology Information (NCBI). The sequence data indicated that the partial PcCyc cDNA contained a 143 bp 5'-UTR and 2,010 bp open reading frame (ORF), encoding 669 amino acids. The ORF contained a typical bHLH/PAS transcription factor structure. Additionally, the translation starting codon was determined as ATG (located at nucleotide 144-146) and stop codon was identified as TGA. The GC and the AT contents in the PcCyc was $43.5 \%$ and $56.5 \%$, respectively (Supplementary Figure S1). The Blastn search in NCBI showed a nucleotide homology similarity at the level of $75 \%-93 \%$. The resulted PcCyc cDNA sequence was deposited in the NCBI GenBank under accession numbers MN908587 and MN939545. The PcClk cDNA was $1,940 \mathrm{bp}$ in length and contained a 183 $\mathrm{bp}$ of the $3^{\prime}$-UTR. The open reading frame (ORF) contained 1,182 bp which encoding 393 amino acids. The ORF of the PcClk gene also contained a typical bHLH/PAS transcription factor structure. The identified the start codon was ATG, the stop codon was TAA (located at 1180-1182) and the obtained PcClk gene sequence has an AT content of $54.8 \%$ and GC content of $45.2 \%$. The NCBI Blastn nucleotide homology similarity interval was $74 \%-98 \%$ (Supplementary Figure S2). The PcClk cDNA sequence was deposited in the GenBank under accession number MN908585. The full-length cDNA sequence of PcCry1 was composed of 3,366 nucleotides, including a $5^{\prime}$-UTR of 116 nucleotides, an open read frame of 1,650 nucleotides, and a $3^{\prime}$-UTR of 240 nucleotides. The ORF encodes 393 amino acids, and the start codon was ATG (located at 117-119), while the stop codon was TGA (located at 1,767-1,769). The AT content of the PcCry1 gene sequence was $55.7 \%$, while the GC content was $44.3 \%$ (Supplementary Figure S3). The complete PcCry1 cDNA sequence was deposited in the GenBank database (accession no. MN908586).

\section{Phylogenetic Analysis}

The phylogenetic tree was constructed based on CYC and CLK protein homologous sequences using maximum likelihood method. The $\mathrm{ML}$ tree revealed two major subgroups; one branch comprised insects (marked in yellow), while the second one included crustaceans. Interestingly, the tree showed that the $P c C y c$ gene was clustered with $C y c$ genes of crustaceans, being very related to $C y c$ gene of Pacifastacus leniusculus, with an amino acid similarity of $93 \%$ (Figure 1). The present result supported wide-known phylogenetic relationship, clustering of the crustaceans CLKs into two separate monophyletic clades. The PCCLK was most related to CLK of Pacifastacus leniusculus (Figure 2). The PCCRY1 was clustered with two CRY1 proteins of other crustaceans. More specifically, it was most closely related to Euphausia superba CRY1, being placed in the joint group together with sequence of Hyalella azteca among all analyzed crustaceans' sequences (Figure 3).

Table 1. Primers used for real-time quantification PCR detection

\begin{tabular}{lll}
\hline Primer & Sequence $\left(5^{\prime}-3^{\prime}\right)$ & Purpose \\
\hline q $\beta$-actin-F & GCACCATCCACCATGAAGATTA & qRT-PCR \\
q $\beta$-actin-R & CGTGAAAGGGAAGCCAAGATG & qRT-PCR \\
qCycle-F & CYGATGTTCCACAGGGACTTAC & qRT-PCR \\
qCycle-R & GAATCGGCCTCCTCTTTCAA & qRT-PCR \\
qClk-F & AAGATGGAGTGCTGGACTTTAG & qRT-PCR \\
qClk-R & GCATAAGGGAGCTCTGAAACAA & qRT-PCR \\
qCry-F & AGTCAGTGCAACGAGCTGCGAAAT & qRT-PCR \\
qCry-R & ACGTGGAGGTGATGGGTAGTGGTC & qRT-PCR \\
\hline
\end{tabular}




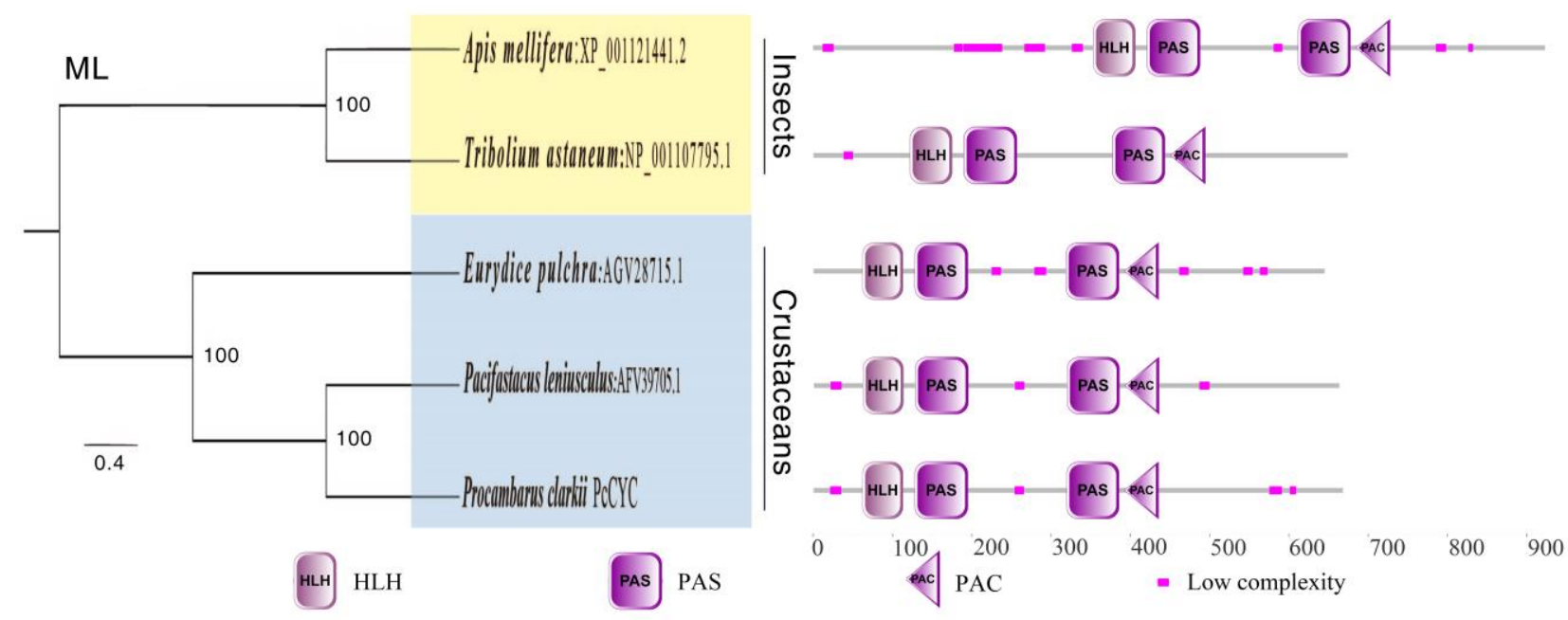

Figure 1. Phylogenetic analysis of CYC and its homologs. The values on the tree nodes are Neighbor-Joining bootstrap values and different branches are covered with specific colors. The domain structures of CYC are shown and their motifs are indicated by separate colors and shapes.

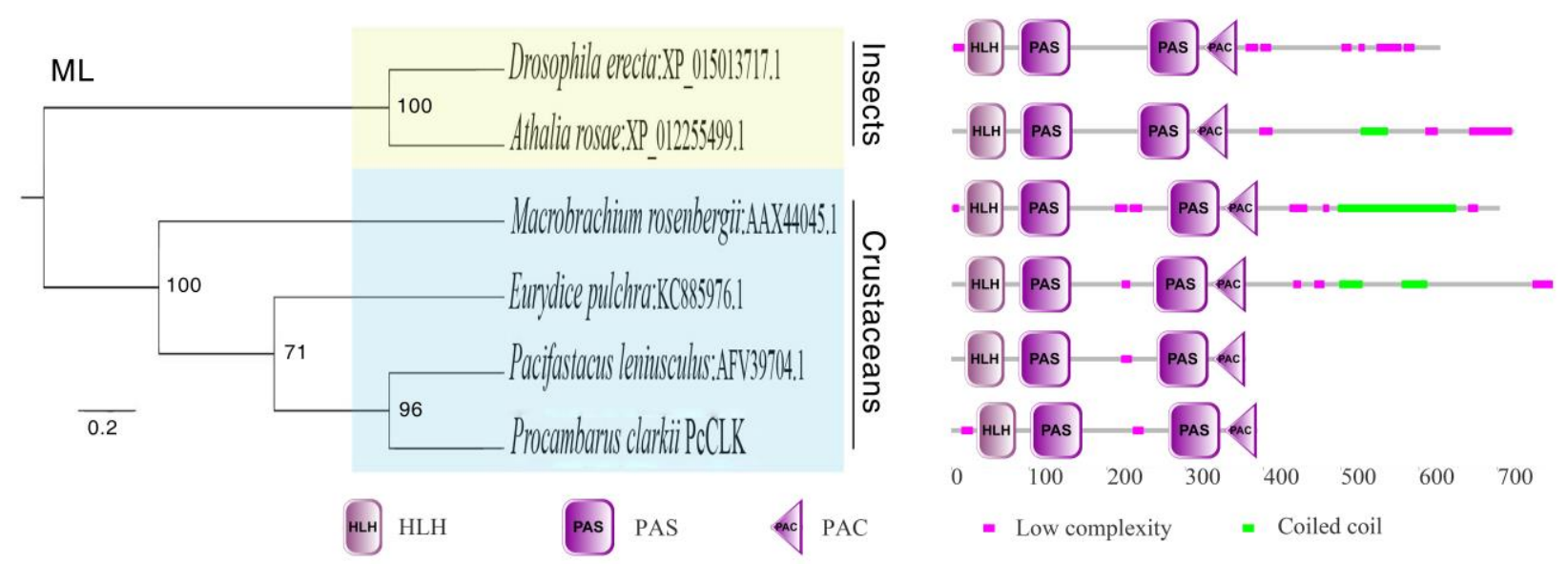

Figure 2. Phylogenetic analysis of CLK and its homologs. The values on the tree nodes are Neighbor-Joining bootstrap values and different branches are covered with specific colors. The domain structures of CLK are shown and their motifs are indicated by separate colors and shapes.
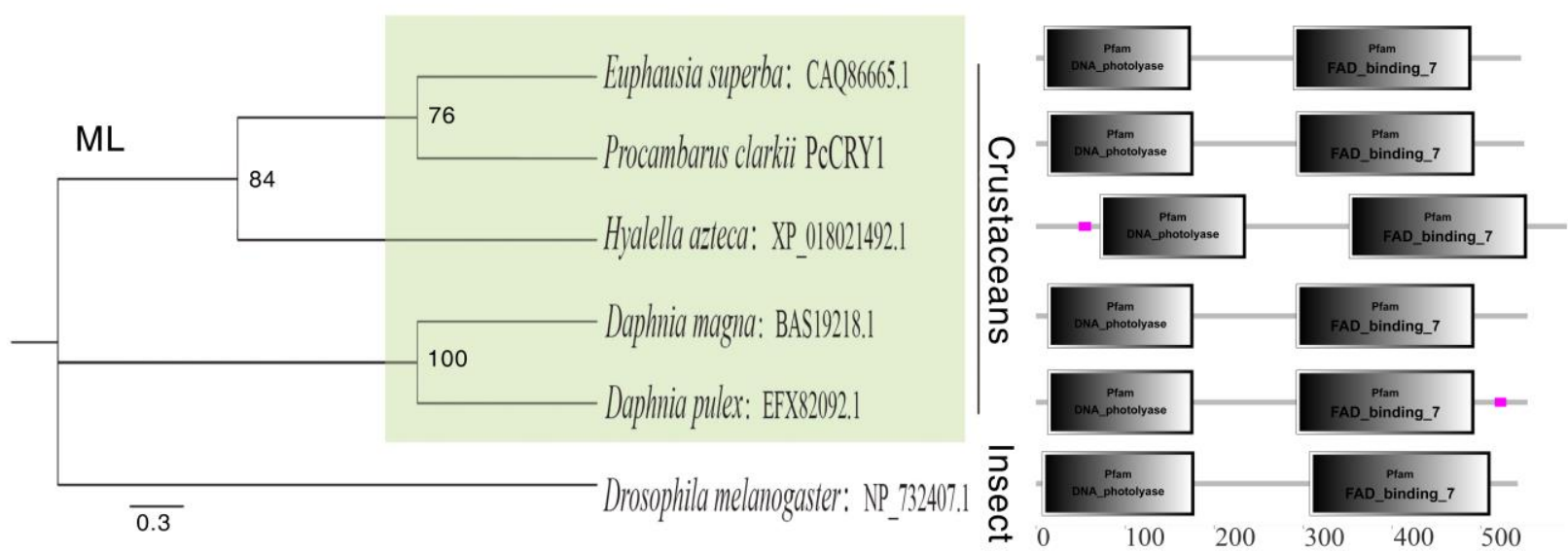

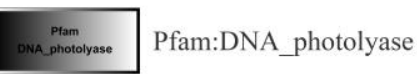

$\underset{\text { FAD_binding_7 }}{\text { Pram Pfam:FAD_blinding_7 }}$ = Low complexity

Figure 3. Phylogenetic analysis of CRY1 and its homologs. The values on the tree nodes are Neighbor-Joining bootstrap values and different branches are covered with specific colors. The domain structures of CRY1 are shown and their motifs are indicated by separate colors and shapes. 


\section{Structural Analyses}

Protein motif domains scanning from SMART diagram database indicated that both PCCYC and PCCLK proteins contain a BHLH/PAS domain complex, which includes one helix-loop-helix $(\mathrm{HLH})$ and two Per-ArntSim (PAS) domains. In turns, two domains were identified in the PcCRY1 protein. One was PHR (photolyaserelated), the homologous sequence of $\mathrm{N}$ terminal and photolyase, which was a region that binds to FMN (flavin mononucleotide). The second one was the C-terminus, which had no obvious homologous sequence with the known protein region and was a binding region with other proteins. Motif search results indicated that the PcCYC protein may contain 19 casein kinase II (CK2) phosphorylation sites, 14 protein kinase $\mathrm{C}$ (PKC) phosphorylation sites, 12 myristoylation sites, etc. The PCCLK protein may contain five casein kinase II (CK2) phosphorylation sites, and seven protein kinase $C$ (PKC) phosphorylation sites, etc. Moreover, the PcCRY1 protein may include the following functional motifs: 7 casein kinase II (CK2) phosphorylation sites, 8 protein kinase $C$ (PKC) phosphorylation sites, and 4 myristoylation sites, etc. The three-dimensional structure analysis of the PcCYC revealed that it contains $11 \alpha$ helices, $12 \beta$-sheets, and 24 irregular curls. The 3-D structure of the PcCLK includes $8 \alpha$ helices, $13 \beta$-sheets, and 22 irregular curls. The PcCRY1 consists of $18 \alpha$ helices, $6 \beta$-sheets, and 25 irregular curls (Supplementary Figure S4 A-C).
The mRNA Expression Patterns of the PcCyc, PcClk and PcCry1 in Different Tissues

Under three lighting conditions, we investigated the mRNA expression patterns of the PcCyc, PcClk, and PcCry1 in different tissues (brain, eyestalk, and hepatopancreas) of $P$. clarkii by RT-qPCR technique. It can be seen that no matter how the light changes, the PcCyc gene basically follows the 24-hour rhythm oscillation in eyestalk and hepatopancreas, and the rhythm oscillation in brain was broken with the change of the photoperiod. In this study, under the photoperiod condition of 12LD per day, the PcCyc gene in brain and eyestalk basically had a similar expression pattern, but under the continuous darkening condition for $24 \mathrm{~h}$ (24DD), this regularity was disrupted. Under the 24DD condition, the peak of the $P c C y c$ gene expression in the eyestalk was 4 hours earlier than that under 12LD condition. As for 72DD, the rhythm oscillation recovered, but it was slightly different from the rhythm of $12 \mathrm{LD}$ (Figure 4).

The results of RT-qPCR showed that the PcClk gene basically follows a 24-hour rhythm oscillation in the brain, eyestalk and hepatopancreas in any of three lighting conditions, while the 24DD rhythm oscillation in the brain deviates slightly. Under the 12LD condition, the expression levels of the PcClk gene in brain and eyestalk were similar, but the similarity was changed under 24DD continuous darkening. However, the expression of the PcClk mRNA was oscillated under the
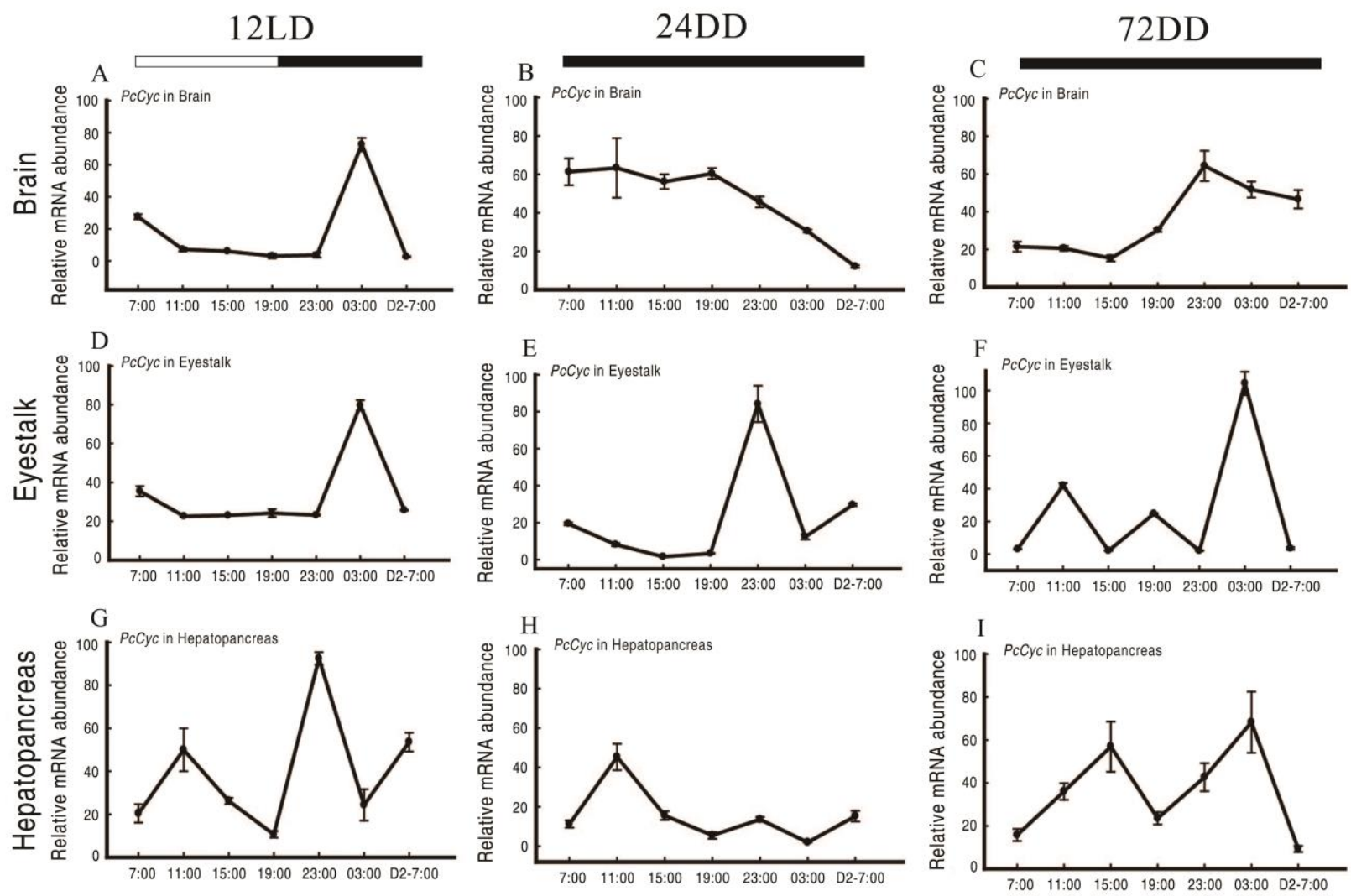

Figure 4. Temporal profiles of the PcCyc mRNA expression in the brain, eyestalk, and hepatopancreas of Procambarus clarkii in $12 \mathrm{LD}$ $(A, D, G), 24 D D(B, E, H)$, and 72DD (C, F, I). D2-7:00, the second day 7:00 am. 
12LD
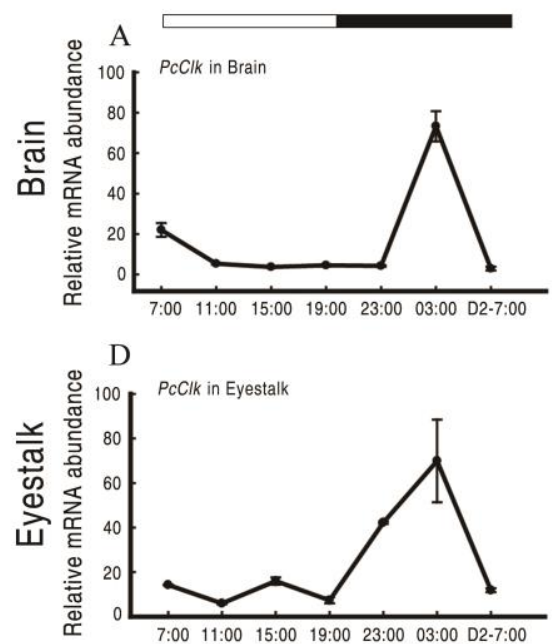

G

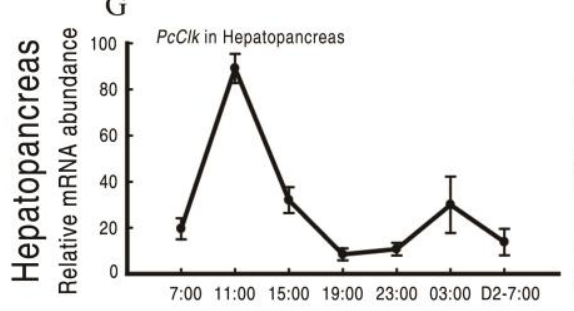

24DD
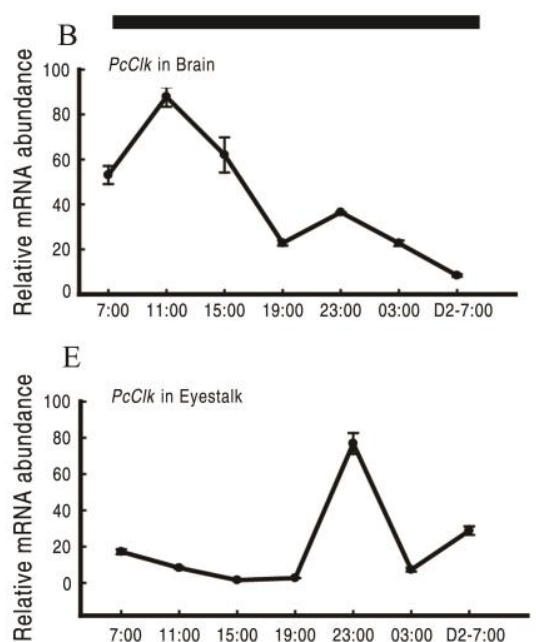
$\mathrm{H}$

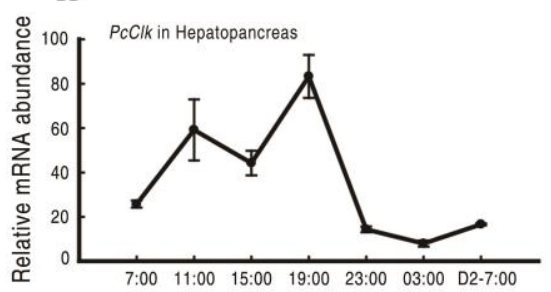

72DD
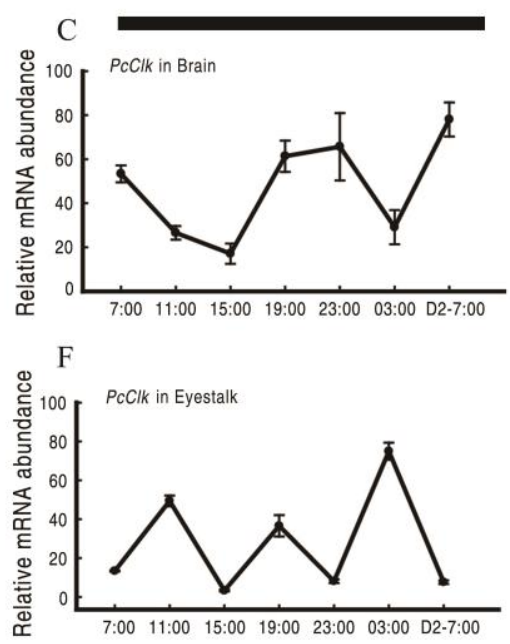

I

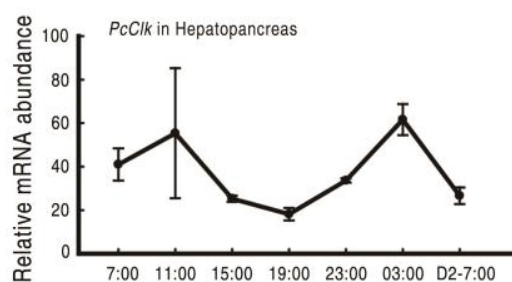

Figure 5. Temporal profiles of the PcClk mRNA expression in the brain, eyestalk, and hepatopancreas of Procambarus clarkii in $12 \mathrm{LD}$ $(A, D, G), 24 D D(B, E, H)$, and 72DD (C, F, I). D2-7:00, the second day 7:00 am.

12LD

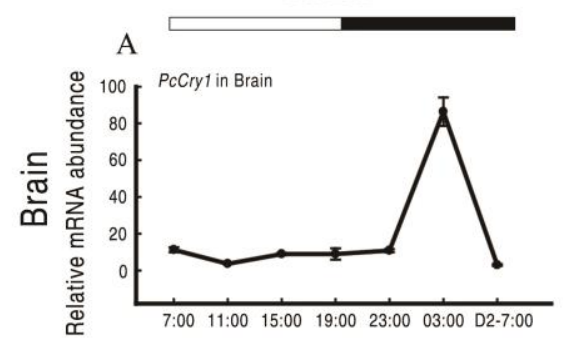

D

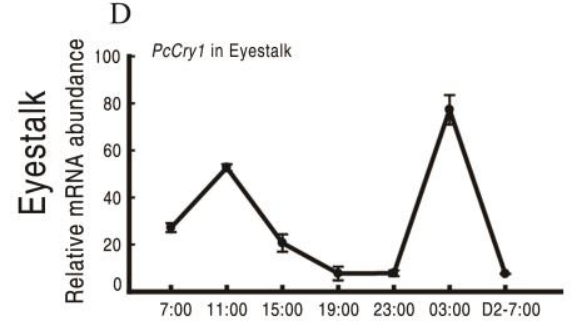

G

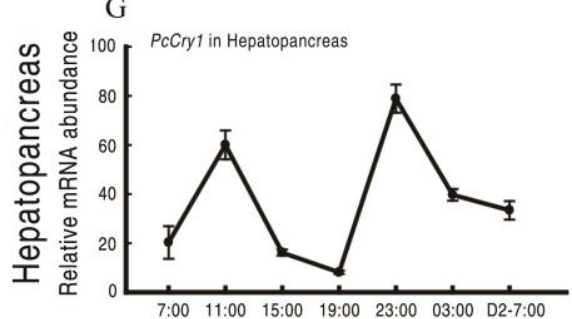

24DD

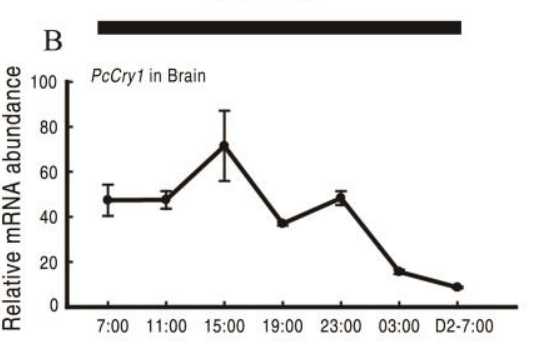

E

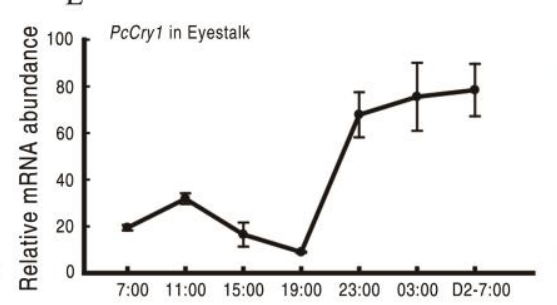

$\mathrm{H}$

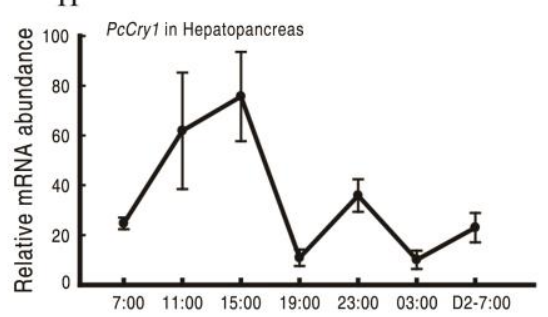

72DD

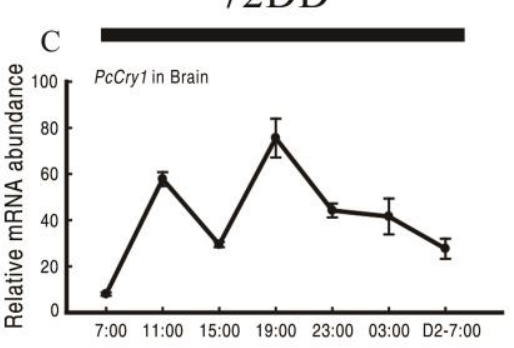

$\mathrm{F}$
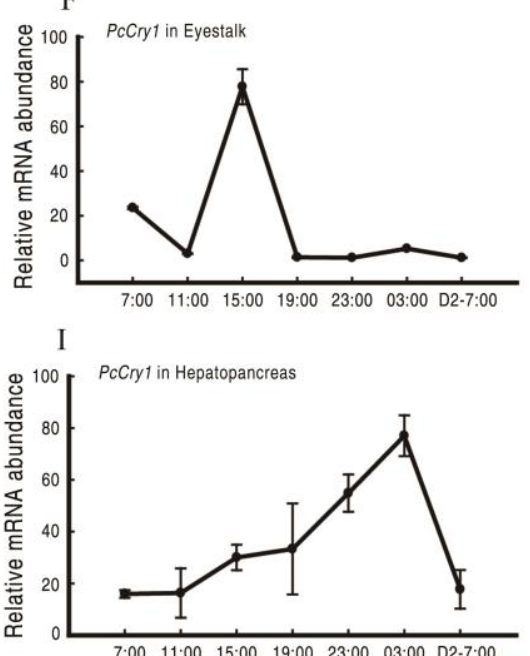

Figure 6. Temporal profiles of the PcCry1 mRNA expression in the brain, eyestalk, and hepatopancreas of Procambarus clarkii in $12 L D(A, D, G), 24 D D(B, E, H)$, and 72DD $(C, F, I) . D 2-7: 00$, the second day 7:00 am. 
72DD condition. In the eyestalk of $12 \mathrm{LD}$, the significant peak of the PcClk mRNA accumulation appeared at 3:00 am. In 24DD, the peak of expression was $4 \mathrm{~h}$ ahead of $12 \mathrm{LD}$. Under the 72DD condition, there were three significant peaks of the PcClk gene expression. But they all basically follow the 24-hour rhythm oscillation. The expression of the PcClk mRNA in hepatopancreas showed a peak delay in 24DD compared with 12LD conditions. In 72DD, the law of rhythm oscillation of 12LD was restored (Figure 5). The mRNA expression levels of PcCry1 gene among sampled tissues basically followed the 24-hour oscillating rhythm under the illumination conditions of 12LD and 72DD (Figure 6). Under the 12LD photoperiod the expression peak of the PcCry1 gene in brain was detected at 3:00 am (Figure $6 \mathrm{~A})$. However, there was confusion in 24DD, and then it gradually showed stability in 72DD. In the eyestalk (Figure 6D), it can be seen that there is a significant peak of the PcCry1 gene expression at 3:00 am and 11:00 am under 12LD. In 24DD, the rhythm was completely disturbed then the expression level of the PcCry1 gene tended to be stable, and there was a peak at 11:00 am. As for hepatopancreas, the first peak appeared at 11:00 am and the second one appeared at 23:00 pm in 12LD. When the light conditions changed to 24DD, the expression of the PcCry1 gene was chaotic and then took stable expression pattern under 72DD condition, where the only one peak appeared at 3:00 am. This indicates that the expression of the PcCry1 gene ran counter to the 24-hour oscillation rhythm in brain and eyestalk under 24DD illumination conditions.

\section{Discussion}

In the present study, we cloned full-length cDNA sequence of cycle and cryptochrome genes, and partial cDNA sequence of clock gene from the red-swamp crayfish Procambarus clarkii. Our analysis revealed the mRNA expression patterns of the examined genes in different tissues of $P$. clarkii and under various diel illumination conditions. The mRNA expression levels of the PcCyc, PcClk, and PcCry1 were rhythmic and analogous in LD cycle in the brain and eyestalk of $P$. clarkii. One significant peak in the $P c C y c$ transcription level during the day in $P$. clarkii was the same as that pattern of expression from the commonly observed unimodal in the whole bodies or selected organs of insects, e.g., mosquitos (Gentile et al., 2006) and aphids (Cortes et al., 2010).

We recorded diel rhythms of the PcCyc mRNA levels in different photoperiods, where under the $24 \mathrm{~h}$ period of constant darkness (24DD) expression of the PcCyc rhythmic oscillation were preserved, except from the brain tissue and the expression of the PcCyc rhythmic oscillation resumed running in 72DD. Under the condition of 72DD, the oscillation rhythm recovers, but it was different from the rhythm law of 12LD. We inferred that $P$. clarkii has an endogenous clock with a daily rhythm in the PcCyc mRNA levels. Similar expression rhythm pattern of $\mathrm{Cyc}$ has been reported for Acyrthosiphon pisum (Cortes et al., 2010), Thermobia domestica (Kamae et al., 2010), and Aedes aegypti (Chahad-Ehlers et al., 2013). Under 12LD condition, the expression of the PcClk had a 24-hour amplitude rhythm in all three tissues. Despite scare state of knowledge on Clk genes in crustaceans, it can be spotted that Clk mRNA abundance was not only found in the nervous system but also some surrounding tissues of Macrobrachium rosenbergii (Yang et al., 2006). Nevertheless, no rhythmic expression of either Clk or Cyc was found by characterizing transcriptional activity of clock genes in different organs of Eurdice pulchra (Zhang et al., 2013). The levels of Clk and Cyc mRNA oscillate over the day in whole Daphnia pulex bodies (Bernatowicz et al., 2016). However, the rhythm was disrupted in 24DD. It has been suggested that the rhythm of the crayfish circadian outputs is coordinated by a neuro-endocrine feedback loop established between sinus gland and protocerebrum (Hernández \&Fuentes-Pardo, 2001; Nelson-Mora et al., 2013).

As the relative mRNA abundance result showed, the PcCyc and PcClk were approximately phase congruent. Similar expression patterns of $\mathrm{Cyc}$ and $\mathrm{Cl}$ was observed in the heads of the mosquitos Aedes aegypti, Anopheles gambiae, and Culex quinquefasciatus (Gentile et al., 2009; Ptitsyn et al., 2011).

Escamilla-Chimal et al. (2010) used antibodies to detect the expression of CLK protein in different tissues under different illumination conditions. The results revealed that CLK protein showed peak protein expression at 12:00 am in eyestalk tissue under 12LD light conditions. In 24DD light conditions, protein expression peaks at 16:00 pm in brain tissue. As for the feedback system, the CYC and the CLK proteins form a heterodimer to function together, so it was speculated that these two genes might have similar mRNA expression levels (Escamilla-Chimal et al., 2010). Accumulation of the clock gene proteins was delayed by 6-8 hours than mRNA production (Price et al., 1998; Kloss et al., 2001). Together, our results on the mRNA expression levels of the $P c C y c$ and PcClk genes of $P$. clarkii in eyestalk were consistent with it. However, compared to in eyestalk, there was a four-hour delay in the rhythmic expression of the two genes in brain, the reason for that needs further research. It was noteworthy that the protein accumulation of the PcCyc and PcClk genes in brain was basically consistent with the rule of protein accumulation delay of $8 \mathrm{~h}$ under 24DD and 72DD conditions. This results support the hypothesis on the formation of heterodimers between CYC protein and CLK protein in the central rhythmic oscillatory tissue; however, further studies are still needed.

In the brain and eyestalk of $P$. clarkii, the oscillations of mRNA expression of the PcCyc and the PcClk genes in the 24DD condition were disrupted compared to the condition of $12 \mathrm{LD}$, while the rhythm 
oscillation recovered at 72DD, but it was different with the previous $12 \mathrm{LD}$ rhythm pattern. The hepatopancreas tissue in P. clarkii belongs to the peripheral oscillator cycle. Delayed phenomenon occurred at the peak period under 24DD conditions, and then the rhythmic oscillation law of 12LD was restored under 72DD illumination conditions. The hepatopancreas mainly regulates the fluctuation of the hormone level in organism, and participates in the regulation of the physiological and biochemical response of the body (Duka \& Ahearn, 2014). As the changes in the environment, the clock genes make corresponding regulatory changes to response. So as time goes on, slowly restore the original rhythmic oscillations, and organism adapts to changes in the environment. Furthermore, we found high fluctuations in brain tissue, demonstrating that the clock genes PcCyc and PcClk have significant endogenous free-running rhythms and are subjected to brain dominance. Similarly, the mammalian's "central clock" of the circadian rhythm control is located in the hypothalamic supraoptic nucleus (SCN) (Coelho et al., 2015). The 24-hour rhythm oscillation cycle of clock genes in mRNA expression levels was also found in E. pulchra (Zhang et al., 2013), but not observed in M. rosenbergii (Yang et al., 2006).

Contrastingly to eyestalk tissue, Fanjul-Moles et al. (2004) detected different CRY protein circulation rhythm in $P$. clarkii brain tissue under different light conditions by application of Drosophila polyclonal antibody detection method. In the present study the PcCry1 gene had a peak expression at 3:00 am, but Fanjul-Moles and colleagues (2004) measured that CRY protein had a peak expression at 19:00 pm, which was not consistent with the clock gene expression to protein accumulation of 6-8 hours delay (Kloss et al., 1998; Kloss et al., 2001). Here we suspected that the CRY protein might be involved in some complex regulatory networks that we didn't find. In the eyestalk, there was a significant peak of expression of the PcCry1 gene at 3:00 am and 11:00 am, and the results from Fanjul-Moles et al. (2004) showed CRY protein at 3:00 am and 19:00 pm has two peak periods, and the time taken from the peak of Cry gene mRNA expression to the peak of protein accumulation may be different due to the different networks involved in the regulation of clock genes under light compensation and darkness conditions. In the peripheral oscillating tissue hepatopancreas, there was a peak of expression at 11:00 am and 23:00 pm. The peak at 11:00 am may be related to the illumination at 7:00 am. In turns, the second expression activity peak at 23:00 pm may be associated to the fact that crayfish were generally nocturnally active (Fanju-Moles et al., 2004). Moreover, different types of cryptochrome gene show different oscillation models in various organisms. In $A$. pisum and $A$. gambiae, cry1 was transcribed constantly throughout the day, but in their heads, only cry2 was rhythmically expressed, with peaks in mRNA accumulation occurring at early and late night (Cortes et al., 2010; Rund, 2011). In D. pulex, crya and cryb, which homologues are cry1 and cry2, show remarkable daily oscillations at the mRNA level (Bernatowicz et al., 2016). Daily differences in mRNA expression described for cry1 in some arthropods, e.g., the presence of peak mRNA accumulation of its homologue (crya) between evening and midnight in D. pulex, differ from that in both brain and peripheral organs of $D$. melanogaster, whose peak appear in the morning/midday (Emery et al., 1998; Zheng et al., 2008). Our study only analyzed mRNA expression levels as a basic inquiry and made inferences. In order to better verify that genes can be combined with protein analysis.

Functional domain analysis of the PcCYC protein revealed a typical bHLH/PAS transcription factor domain, including $1 \mathrm{HLH}$ domain and 2 PAS domains, which is ubiquitous in CYC proteins of Drosophila (Ripperger \& Schibler, 2006), mice (Rudic et al., 2004), and humans (Shirai et al., 2006). Meanwhile, the same domain appeared in the PcCLK protein, which is widespread in CLK proteins of Drosophila (Bae et al., 1998), mouse (Steeves et al., 1999), and Arabidopsis (Whitmore et al., 1998). It was speculated that the domain's E-box region was the binding site of the PcCLK when interacting with other proteins. In the clockregulated network, it can form a heterodimer with the PcCYC protein to activate transcription of the downstream genes Per, Tim, etc, which acts as positive feedback (Escamilla-Chimal et al., 2010). At the same time, the PcClk gene can interact with vrille (vri) and Par Domain Protein 1 (Pdp1) genes to form a second feedback regulation system (Cyran et al., 2003). The result was similar with the previous studies on other crustaceans, such as: M. rosenbergi (Yang et al., 2006) and E. pulchra (Zhang et al., 2013). Therefore, these results confirmed that CLK protein was involved in the clock regulation system and cooperates with BMAL1 protein to activate transcription.

The amino acid sequence of the PcCry1 was blast by homologous sequence alignment, and no other type of Cry gene (e.g. called Cry2 in other species) was obtained in this study. This result supports that the data obtained in the current work have no possibility to detect two proteins products of two different Cry genes in the crayfish (Escamilla-Chimal \& Fanjul-Moles, 2008). Furthermore, the protein may have two domains that were involved in two different functions, just like other species (Green, 2004). To this date, the existence status of both types Cry gene in P. clarkii have not been determined. Previous studies revealed that Drosophila has only one CRY protein (dCRY), which functions mainly as a blue light receptor (Emery et al., 1998). Mice have two CRY proteins (mCRY1 and mCRY2), which are not directly used as photoreceptors but as effective transcriptional repressors (Reppert \& Weaver, 2002). In turns, two CRY proteins (dpCRY1 and dpCRY2) are present in monarch butterfly Danaus plexippus. The dpCRY1 is a degenerating photoreceptor of the function similar to dCRY. The function of dpCRY2 is comparable to $\mathrm{MCRY1}$, being a powerful transcription factor (Zhu et 
al., 2005). The results in our study showed that the PcCry1 might be controlled by a light-induced suppression mechanism that is known to regulate cry 1 in other insets. The function of the PcCRY1 protein in $P$. clarkii seems to be more similar to the dCRY protein of Drosophila. The PcCRY1 protein contained a typical PHR domain that was similar to DNA photolyase but did not possess DNA repair activity (Hitomi et al., 2000; Ng \& Pakrasi, 2001). PHR binds to FAD and tetrahydrofolate, being a region that senses light signals (Brudler et al., 2003). Nevertheless, further studies are needed for exploring the regulatory functions and mechanism of the studies clock genes in the red swamp crayfish $P$. clarkii.

\section{Conclusion}

In summary, we cloned and characterized fulllength or partial cDNA sequence of the major clock genes PcCyc, PcClk, PcCry1 from crayfish Procambarus clarkii. This study focused on the mRNA expression levels of the circadian clock genes, i.e. PcCyc, PcClk, PcCry1 in brain, eyestalk, and hepatopancreas tissues of $P$. clarkii under different light conditions (12LD, 24DD, and $72 \mathrm{DD}$ ). Our results revealed original data on the mRNA expression of these three core clock genes in different tissues of $P$. clarkii under various illumination conditions. The mRNA expression levels of the PcCyc, PcClk, and PcCry1 were rhythmic and analogous under LD cycle in the brain and eyestalk of $P$. clarkii. The examined clock genes had significant endogenous freerunning rhythms and were dominated by the brain. This results support the statement on the formation of heterodimers between PCCYC and PCCLK proteins in the central rhythmic oscillatory tissue.

\section{Electronic Supplementary Material}

This article contains supplementary figures and appendix data (Appendix data file S1), which are available to authorized users.

\section{Acknowledgements}

The authors appreciate the anonymous reviewers for numerous thoughtful comments and language refinement on the manuscript. This work was supported by grants from the National Natural Science Foundation of China (Grants No. 31672269 and 31000949 to JY and 31000954 to $\mathrm{PL}$ ), the Natural Science Foundation of the Jiangsu Higher Education Institutions of China (19KJA330001 to PL), the Natural Science Foundation of Jiangsu Province (BK20181076 to WC), the Qing Lan Project of Jiangsu Province (BK2019SZJS-003 to WC), Program of Natural Science Research of Jiangsu Higher Education Institutions of China (17KJD240001 to PL), the Priority Academic Program Development of Jiangsu Higher Education Institutions (PAPD), and Top-notch
Academic Programs Project of Jiangsu Higher Education Institutions (TAPP, PPZY2015B117).

\section{References}

Bae, K., Lee, C., Sidote, D., Chuang, K. Y., \& Edery, I. (1998). Circadian regulation of a Drosophila homolog of the mammalian Clock gene: PER and TIM function as positive regulators. Molecular and Cellular Biology, 18(10), 61426151. http://doi.org/10.1128/mcb.18.10.6142

Beaver, L. M., \& Giebultowicz, J. M. (2004). Regulation of copulation duration by period and timeless in Drosophila melanogaster. Current Biology, 14(16), 1492-1497. http://doi.org/10.1016/j.cub.2004.08.022

Bendtsen, J. D., Nielsen, H., von Heijne, G., \& Brunak, S. (2004). Improved prediction of signal peptides: SignalP 3.0. Journal of Molecular Biology, 340(4), 783-795. http://doi.org/10.1016/j.jmb.2004.05.028

Bernatowicz, P. P., Kotwica-Rolinska, J., Joachimiak, E., Sikora, A., Polanska, M. A., Pijanowska, J., \& Bebas, P. (2016). Temporal expression of the clock genes in the water flea Daphnia pulex (Crustacea: Cladocera). Journal of Experimental Zoology Part A-Ecological Genetics and Physiology, 325(4), 233-254. http://doi.org/10.1002/jez.2015

Boothroyd, C. E., Wijnen, H., Naef, F., Saez, L., \& Young, M. W. (2007). Integration of light and temperature in the regulation of circadian gene expression in Drosophila. PLoS Genetics, 3(4), e54. http://doi.org/10.1371/journal.pgen.0030054

Brudler, R., Hitomi, K., Daiyasu, H., Toh, H., Kucho, K., Ishiura, M., Kanehisa, M., Roberts, V. A., Todo, T., Tainer, J. A., \&Getzoff, E. D. (2003). Identification of a new cryptochrome class: Structure, function, and evolution. Molecular Cell, 11(1), 59-67. http://doi.org/ 10.1016/s1097-2765(03)00008-x

Chahad-Ehlers, S., Gentile, C., Lima, J. B., Peixoto, A. A., \& Bruno, R. V. (2013). Analysis of cycle gene expression in Aedes aegypti brains by in situ hybridization. PLOS ONE, 8(1), e52559. http://doi.org/10.1371/journal.pone.0052559

Chesmore, K. N., Watson, W. H., 3rd, \& Chabot, C. C. (2016). Identification of putative circadian clock genes in the American horseshoe crab, Limulus polyphemus. Comparative Biochemistry and Physiology. Part $D$, Genomics and Proteomics, 19, 45-61. http:// doi.org/10.1016/j.cbd.2016.06.001

Christie, A. E., Yu, A., Roncalli, V., Pascual, M. G., Cieslak, M. C., Warner, A. N., Lameyer, T. J., Stanhope, M. E., Dickinson, P. S., \& Hull, J. J. (2018). Molecular evidence for an intrinsic circadian pacemaker in the cardiac ganglion of the American lobster, Homarus americanus - Is diel cycling of heartbeat frequency controlled by a peripheral clock system? Marine genomics, 41, 19-30. https://doi.org/10.1016/j.margen.2018.07.001

Coelho, L. A., Peres, R., Amaral, F. G., Reiter, R. J., \& CipollaNeto, J. (2015). Daily differential expression of melatonin-related genes and clock genes in rat cumulusoocyte complex: changes after pinealectomy. Journal of Pineal Research, 58(4), 490-499. http://doi.org/10.1111/jpi.12234

Cortes, T., Ortiz-Rivas, B., \& Martinez-Torres, D. (2010). Identification and characterization of circadian clock genes in the pea aphid Acyrthosiphon pisum. Insect Molecular Biology, 19(Suppl 2), 123-139. 
http://doi.org/10.1111/j.1365-2583.2009.00931.x

Cyran, S. A., Buchsbaum, A. M., Reddy, K. L., Lin, M. C., Glossop, N. R., Hardin, P. E., Young, M. W., Storti, R. V., \& Blau, J. (2003). vrille, $P d p 1$, and dClock form a second feedback loop in the Drosophila circadian clock. Cell, 112(3), 329341. http://doi.org/10.1016/s0092-8674(03)00074-6

Duka, A., \& Ahearn, G. A. (2014). Comparative cation dependency of sugar transport by crustacean hepatopancreas and intestine. Biology Open, 3(7), 635643. http:// doi.org/10.1242/bio.20148904

Emery, P., So, W. V., Kaneko, M., Hall, J. C., \& Rosbash, M. (1998). CRY, a Drosophila clock and light-regulated cryptochrome, is a major contributor to circadian rhythm resetting and photosensitivity. Cell, 95(5), 669679. http://doi.org/10.1016/s0092-8674(00)81637-2

Escamilla-Chimal, E. G., \& Fanjul-Moles, M. L. (2008). Daily and circadian expression of cryptochrome during the ontogeny of crayfish. Comparative Biochemistry and Physiology Part A, Molecular and Integrative Physiology, 151(3), 461-470.

http:// doi.org/10.1016/j.cbpa.2007.02.014

Escamilla-Chimal, E. G., Velazquez-Amado, R. M., Fiordelisio, T., \& Fanjul-Moles, M. L. (2010). Putative pacemakers of crayfish show clock proteins interlocked with circadian oscillations. Journal of Experimental Biology, 213(21), 3723-3733. http:// doi.org/10.1242/jeb.047548

Fanjul-Moles, M. L., Escamilla-Chimal, E. G., Gloria-Soria, A., \& Hernandez-Herrera, G. (2004). The crayfish Procambarus clarkii CRY shows daily and circadian variation. Journal of Experimental Biology, 207(9), 1453-1460. http:// doi.org/10.1242/jeb.00900

Fanjul-Moles, M. L., \& Prieto-Sagredo, J. (2003). The circadian system of crayfish: a developmental approach. Microscopy Research Technique, 60(3), 291-301. http://doi.org/ 10.1002/jemt.10268

Fuhr, L., Abreu, M., Pett, P., \& Relogio, A. (2015). Circadian systems biology: When time matters. Computational and Structural Biotechnology Journal, 13, 417-426. http:// doi.org/10.1016/j.csbj.2015.07.001

Garcia, U., \& Arechiga, H. (1998). Regulation of crustacean neurosecretory cell activity. Cellular and Molecular Neurobiology, 18(1), 81-99. http:// doi.org/10.1023/a:1022527210808

Gegear, R. J., Casselman, A., Waddell, S., \& Reppert, S. M. (2008). Cryptochrome mediates light-dependent magnetosensitivity in Drosophila. Nature, 454(7207), 1014-1018. http://doi.org/10.1038/nature07183

Gentile, C., Meireles-Filho, A. C., Britto, C., Lima, J. B., Valle, D., \& Peixoto, A. A. (2006). Cloning and daily expression of the timeless gene in Aedes aegypti (Diptera: Culicidae). Insect Biochemistry and Molecular Biology, 36(11), 878884. http:// doi.org/10.1016/j.ibmb.2006.08.008

Gentile, C., Rivas, G. B., Meireles-Filho, A. C., Lima, J. B., \& Peixoto, A. A. (2009). Circadian expression of clock genes in two mosquito disease vectors: cry2 is different. Journal of Biological Rhythms, 24(6), 444-451. http:// doi.org/10.1177/0748730409349169

Goto, S. G. (2013). Roles of circadian clock genes in insect photoperiodism. Entomological Science, 16(1), 1-16. http://doi.org/10.1111/ens.12000

Grabek, K. R., \& Chabot, C. C. (2012). Daily Rhythms of PERIOD protein in the eyestalk of the American lobster, Homarus americanus. Marine and Freshwater Behaviour And Physiology, 45(4), 269-279.

http://doi.org/10.1080/10236244.2012.730209
Green, C. B. (2004). Cryptochromes: tail-ored for distinct functions. Current Biology, 14(19), R847-849. http://doi.org/10.1016/j.cub.2004.09.040

Heyers, D., Manns, M., Luksch, H., Güntürkün, O., \& Mouritsen, H. (2007). A visual pathway links brain structures active during magnetic compass orientation in migratory birds. PLOS ONE, 2(9), e937. http://doi:10.1371/journal.pone.0000937.

Hitomi, K., Okamoto, K., Daiyasu, H., Miyashita, H., Iwai, S., Toh, H., Ishiura, M., \& Todo, T. (2000). Bacterial cryptochrome and photolyase: characterization of two photolyase-like genes of Synechocystis sp. PCC 6803. Nucleic Acids Research, 28(12), 2353-2362. http://doi.org/10.1093/nar/28.12.2353

Hoang, N., Schleicher, E., Kacprzak, S., Bouly, J. P., Picot, M., Wu, W., Berndt, A., Wolf, E., Bittl, R., \& Ahmad, M. (2008). Human and Drosophila cryptochromes are light activated by flavin photoreduction in living cells. PLOS Biology, 6(7), e160. doi: 10.1371/journal.pbio.0060160.

Hulo, N., Bairoch, A., Bulliard, V., Cerutti, L., Cuche, B. A., de Castro, E., Lachaize, C., Langendijk-Genevaux, P. S., \& Sigrist, C. J. (2008). The 20 years of PROSITE. Nucleic Acids Research, 36(Database issue), D245-249. http://doi.org/10.1093/nar/gkm977

Ikeda, M., \& Nomura, M. (1997). cDNA cloning and tissuespecific expression of a novel basic helix-loop-helix/PAS protein (BMAL1) and identification of alternatively spliced variants with alternative translation initiation site usage. Biochemical and Biophysical Research Communications, 233(1), 258-264. http://doi.org/10.1006/bbrc.1997.6371

Kamae, Y., Tanaka, F., \& Tomioka, K. (2010). Molecular cloning and functional analysis of the clock genes, Clock and cycle, in the firebrat Thermobia domestica. Journal of Insect Physiology, 56(9), 1291-1299. http://doi.org/10.1016/j.jinsphys.2010.04.012

King, D. P., Zhao, Y., Sangoram, A. M., Wilsbacher, L. D., Tanaka, M., Antoch, M. P., Steeves, T. D., Vitaterna, M. H., Kornhauser, J. M., Lowrey, P. L., Turek, F. W., \& Takahashi, J. S. (1997). Positional cloning of the mouse circadian clock gene. Cell, 89(4), 641-653. http://doi.org/10.1016/s0092-8674(00)80245-7

Kloss, B., Price, J. L., Saez, L., Blau, J., Rothenfluh, A., Wesley, C. S., \& Young, M. W. (1998). The Drosophila clock gene double-time encodes a protein closely related to human casein kinase le. Cell, 94(1), 97-107. http://doi.org/10.1016/s0092-8674(00)81225-8

Kloss, B., Rothenfluh, A., Young, M. W., \& Saez, L. (2001). Phosphorylation of PERIOD is influenced by cycling physical associations of double-time, PERIOD, and timeless in the Drosophila clock. Neuron, 30(3), 699-706. http:// doi.org/10.1016/s0896-6273(01)00320-8

Lee, C., Bae, K., \& Edery, I. (1998). The Drosophila CLOCK protein undergoes daily rhythms in abundance, phosphorylation, and interactions with the PER-TIM complex. Neuron, 21(4), 857-867. http://doi.org/10.1016/s0896-6273(00)80601-7

Livak, K. J., \& Schmittgen, T. D. (2001). Analysis of relative gene expression data using real-time quantitative PCR and the 2- $\triangle \Delta C T$ method. Methods, 25(4), 402-408. https://doi.org/10.1006/meth.2001.1262.

Manfrin, C., Tom, M., De Moro, G., Gerdol, M., Giulianini, P. G., \& Pallavicini, A. (2015). The eyestalk transcriptome of red swamp crayfish Procambarus clarkii. Gene, 557(1), 28-34. https://doi.org/10.1016/j.gene.2014.12.001 
Nelson-Mora, J., Prieto-Sagredo, J., Loredo-Ranjel, R., \& FanjulMoles, M. L. (2013). Putative pacemakers in the eyestalk and brain of the crayfish Procambarus clarkii show circadian oscillations in levels of mRNA for crustacean hyperglycemic hormone. PLOS ONE, 8(12), e83937. http://doi.org/10.1371/journal.pone.0083937

Ng, W. O., \& Pakrasi, H. B. (2001). DNA photolyase homologs are the major UV resistance factors in the cyanobacterium Synechocystis sp. PCC 6803. Molecular and General Genetics, 264(6), 924-930. http://doi.org/10.1007/s004380000383

Nielsen, H., \& Krogh, A. (1998). Prediction of signal peptides and signal anchors by a hidden Markov model. Proceedings Sixth International Conference on Intelligent Systems for Molecular Biology, 6, 122-130. https://www.researchgate.net/publication/13503542

O'Grady, J. F., Hoelters, L. S., Swain, M. T., \& Wilcockson, D. C. (2016). Identification and temporal expression of putative circadian clock transcripts in the amphipod crustacean Talitrus saltator. PeerJ, 4, e2555. http://doi.org/10.7717/peerj.2555

Ozturk, N., Selby, C. P., Annayev, Y., Zhong, D., \& Sancar, A. (2011). Reaction mechanism of Drosophila cryptochrome. Proceedings of the National Academy of Sciences of the United States of America, 108(2), 516521. http://doi:10.1073/pnas.1017093108.

Petersen, T. N., Brunak, S., von Heijne, G., Nielsen, H. (2011). SignalP 4.0: discriminating signal peptides from transmembrane regions. Nature Methods, 8(10), 785786. http:// doi.org/10.1038/nmeth.1701.

Plautz, J. D., Kaneko, M., Hall, J. C., \& Kay, S. A. (1997). Independent photoreceptive circadian clocks throughout Drosophila. Science, 278(5343), 1632-1635. http:// doi.org/10.1126/science.278.5343.1632

Price, J. L., Blau, J., Rothenfluh, A., Abodeely, M., Kloss, B., \& Young, M. W. (1998). double-time is a novel Drosophila clock gene that regulates PERIOD protein accumulation. Cell, 94(1), 83-95. http://doi.org/10.1016/s00928674(00)81224-6

Ptitsyn, A. A., Reyes-Solis, G., Saavedra-Rodriguez, K., Betz, J., Suchman, E. L., Carlson, J. O., \& Black, W. C. (2011). Rhythms and synchronization patterns in gene expression in the Aedes aegypti mosquito. BMC Genomics, 12, 153. http://doi.org/10.1186/1471-216412-153

Reppert, S. M., \& Weaver, D. R. (2002). Coordination of circadian timing in mammals. Nature, 418(6901), 935941. http://doi.org/10.1038/nature00965

Ripperger, J. A., \& Schibler, U. (2006). Rhythmic CLOCK-BMAL1 binding to multiple E-box motifs drives circadian $D b p$ transcription and chromatin transitions. Nature Genetics, 38(3), 369-374.

http://doi.org/10.1038/ng1738

Rudic, R. D., McNamara, P., Curtis, A. M., Boston, R. C., Panda, S., Hogenesch, J. B., \& Fitzgerald, G. A. (2004). BMAL1 and CLOCK, two essential components of the circadian clock, are involved in glucose homeostasis. PLoS Biology, 2(11), e377. http://doi.org/10.1371/journal.pbio.0020377

Rund, D. (2011). Genotyping chronic lymphocytic leukemia in China: East meets West. Leukemia \& Lymphoma, 52(6), 941-942. http:// doi.org/10.3109/10428194.2011.579211

Sancar, A. (2003). Structure and function of DNA photolyase and cryptochrome blue-light photoreceptors. Chemical
Reviews, 103(6), 2203-2237.

http:// doi.org/10.1021/cr0204348

Sancar, C., Sancar, G., Ha, N., Cesbron, F., \& Brunner, M. (2015). Dawn- and dusk-phased circadian transcription rhythms coordinate anabolic and catabolic functions in Neurospora. BMC Biology, 13, 17. http://doi.org/10.1186/s12915-015-0126-4

Saunders, D. S. (2010). Controversial aspects of photoperiodism in insects and mites. Journal of Insect Physiology, 56(11), 1491-1502. http:// doi.org/10.1016/j.jinsphys.2010.05.002

Shen, H. S., Hu, Y. C., Ma, Y. C., Zhou, X., Xu, Z. H., Shui, Y., Li, C., Xu, P., \& Sun, X. W. (2014). In-depth transcriptome analysis of the red swamp crayfish Procambarus clarkii. PLOS ONE, 9(10), e110548 http://doi.org/10.1371/journal.pone.0110548

Shirai, H., Oishi, K., \& Ishida, N. (2006). Bidirectional CLOCK/BMAL1-dependent circadian gene regulation by retinoic acid in vitro. Biochemical and Biophysical Research Communications, 351(2), 387-391. http://doi.org/10.1016/j.bbrc.2006.10.031

Song, S. H., Oztürk, N., Denaro, T. R., Arat, N. O., Kao, Y. T., Zhu, H., Zhong, D., Reppert, S. M., \& Sancar, A. (2007). Formation and function of flavin anion radical in cryptochrome 1 blue-light photoreceptor of monarch butterfly. The Journal of Biological Chemistry, 282(24), 17608-17612. http://doi:10.1074/jbc.M702874200.

Stanewsky, R. (2002). Clock mechanisms in Drosophila. Cell and Tissue Research, 309(1), 11-26. http://doi.org/10.1007/s00441-002-0569-0

Steeves, T. D., King, D. P., Zhao, Y., Sangoram, A. M., Du, F., Bowcock, A. M., Moore, R. Y., \& Takahashi, J. S. (1999). Molecular cloning and characterization of the human CLOCK gene: expression in the suprachiasmatic nuclei. Genomics, 57(2), 189-200. http://doi.org/10.1006/geno.1998.5675

Rund, S. S., Yoo, B., Alam, C., Green, T., Stephens, M. T., Zeng, E., George, G. F., Sheppard, A. D., Duffield, G. E., Milenkovic, T., \& Pfrender, M. E. (2016). Genome-wide profiling of $24 \mathrm{hr}$ diel rhythmicity in the water flea, Daphnia pulex: network analysis reveals rhythmic gene expression and enhances functional gene annotation. BMC Genomics, 17, 653. http://doi.org/10.1186/s12864016-2998-2

Tilden, A. R., McCoole, M. D., Harmon, S. M., Baer, K. N., \& Christie, A. E. (2011). Genomic identification of a putative circadian system in the cladoceran crustacean Daphnia pulex. Comparative Biochemistry and Physiology Part D, Genomics and Proteomics, 6(3), 282309. http://doi.org/10.1016/j.cbd.2011.06.002

Whitmore, D., Foulkes, N. S., Strahle, U., \& Sassone-Corsi, P. (1998). Zebrafish Clock rhythmic expression reveals independent peripheral circadian oscillators. Nature Neuroscience, 1(8), 701-707. http://doi.org/10.1038/3703

Yan, S., Ni, H., Li, H. T., Zhang, J., Liu, X. X., \& Zhang, Q. W. (2013). Molecular cloning, characterization, and mRNA expression of two cryptochrome genes in Helicoverpa armigera (Lepidoptera: Noctuidae). Journal of Economic Entomology, 106(1), 450-462. http://doi.org/10.1603/EC12290

Yang, J. S., Dai, Z. M., Yang, F., \& Yang, W. J. (2006). Molecular cloning of Clock cDNA from the prawn, Macrobrachium rosenbergii. Brain Research, 1067(1), 13-24. http://doi.org/10.1016/j.brainres.2005.10.003 
Young, M. W., \& Kay, S. A. (2001). Time zones: a comparative genetics of circadian clocks. Nature Reviews Genetics, 2(9), 702-715. http://doi.org/10.1038/35088576

Zhang, L., Hastings, M. H., Green, E. W., Tauber, E., Sladek, M., Webster, S. G., Kyriacou, C. P., \& Wilcockson, D. C. (2013). Dissociation of circadian and circatidal timekeeping in the marine crustacean Eurydice pulchra. Current Biology, 23(19), 1863-1873. http:// doi.org/10.1016/j.cub.2013.08.038
Zheng, H., Ng, F. S., Liu, Y. X., \& Hardin, P. E. (2008). Spatial and circadian regulation of cry in Drosophila. Journal of Biological Rhythms, 23(4), 283-295. http://doi.org/10.1177/0748730408318566

Zhu, H., Yuan, Q., Briscoe, A. D., Froy, O., Casselman, A., \& Reppert, S. M. (2005). The two CRYs of the butterfly. Current Biology, 15(23), R953-954. http://doi.org/10.1016/j.cub.2005.11.030 